\title{
Influence of Warm-Up Intensity on Submaximal Exercise 0xygen Uptake in Iranian Female National Futsal Players
}

\author{
Najmeh Rezaei Nejad ${ }^{1}$, Parvaneh Nazarali ${ }^{2}$, Hamid Rajabi ${ }^{3}$ and Rostam Alizadeh ${ }^{4 *}$ \\ ${ }^{1}$ PhD Student of Physical Education and Sport Sciences, Mazandaran University, Iran \\ ${ }^{2}$ Assistant Professor in Physical Education and Sport Sciences, Faculty of Physical Education of Alzahra University, Iran \\ ${ }^{3}$ Assistant Professor in Physical Education and Sport Sciences, Faculty of Physical Education, Kharazmi University, Iran \\ ${ }^{4}$ Department of Sports Science, Ilam University, Iran
}

Submission: May 01, 2018; Published: May 08, 2018

*Corresponding author: Rostam Alizadeh, Department of Sports Science, School of Literature and Humanities, Ilam University, Iran, Email: r.alizadeh@ilam.ac.ir

\begin{abstract}
The purpose of this study was to examine the effects of warm-up intensity on total oxygen uptake and $\mathrm{VO}_{2}$ kinetics (time constants) during submaximal exercise in the Iranian national female futsall player's. The participants of this study were ten Players of Iranian futsal national team (mean \pm SD: age, $22.5 \pm 3.2 \mathrm{yrs}$; weight, $56.04 \pm 6.17 \mathrm{~kg}$; height, $163 \pm 3.68 \mathrm{~cm}$; body fat $\%, 23.5 \pm 3.8 ; \mathrm{BMI}, 21.07 \pm 2.22 \mathrm{~kg} / \mathrm{m}^{2} ; \mathrm{VO}_{2} \mathrm{max}, 46.05 \pm 4.61$ $\mathrm{ml} . \mathrm{kg}^{-1} \cdot \mathrm{min}^{-1}$ ). After measuring of $\mathrm{VO}_{2}$ max and LT in first session, the subjects performed two protocols of warm up (moderate and heavy intensity) and one protocol with-out warm up before sub maximal exercise (80\%LT) in three separated sessions. Respiratory gas exchange measured by Gas Analyzer during the exercise. Repeated measures ANOVA and LSD test were applied for statistical analysis. Total oxygen uptakes were not significant difference after three conditions. After moderate and heavy warm up, third time constants significantly reduced in compare to without warm-up $(\mathrm{p}<0 / 05)$. Also oxygen uptake/time ratio in third time constants significantly increased after moderate and heavy warm up respect to without warm-up $(\mathrm{p}<0 / 05)$. The results suggest that warm up causes reducing the time of reaching to steady state of $\mathrm{O}_{2}$ uptake in sub maximal exercise and this effect is independent to warm up intensity.
\end{abstract}

Keywords: $\mathrm{VO}_{2}$ total; Intensity of warm up; Sub maximal exercise

\section{Introduction}

Oxygen uptake during submaximal exercise $\left(\mathrm{VO}_{2}\right)$ and maximal exercise $\left(\mathrm{VO}_{2} \max \right)$ have an important role in physical performance [1]. Augmentation of whole body $\mathrm{O}_{2}$ consumption $\left(\mathrm{VO}_{2}\right)$ has been proposed to result from acceleration of ratelimiting oxidative phosphorylation reactions, enhanced $\mathrm{O}_{2}$ delivery associated with increased muscle blood flow, and a temperature-induced facilitation of oxyhaemoglobin dissociation [2]. During the transition from rest to exercise, muscle $\mathrm{O}_{2}$ uptake increases with a finite time course, the nature of which may give valuable insights into the underlying control mechanisms of energy production. With respect to exercise intensity, the pulmonary oxygen uptake $\mathrm{VO}_{2}$ on-transient has been characterized by two or three phases [3,4]. The initial delay is usually ascribed to the cardio dynamic phase mainly linked to an increased pulmonary perfusion [3] while the subsequent fundamental phase has generally been reported to closely reflect (within 10\%) the oxygen consumption at the muscle level [5]. However, the rate-limiting steps of $\mathrm{VO}_{2}$ are still not clearly defined. Oxygen uptake kinetics is more important in explanation of sport performance [5] than other parameters of aerobic fitness $\left(\mathrm{VO}_{2}\right.$ max, LT) Because in the endurance performance, earlier attainment of the required $\mathrm{VO}_{2}$ not only reduce the accumulation of metabolites that might impair performance but also 'spare' some limited amount of available anaerobic energy for use later in the race [1]. Several investigators have reported beneficial effects of preliminary (warm-up) exercise during subsequent exercise in human athletes and have attributed these improvements in performance to a variety of mechanisms [6]. More specifically, it has been proposed that warm-up bouts can accelerate the rate-limiting steps in oxidative reactions and improve release of oxygen from haemoglobin and myoglobin [1].

It has also been suggested that warm-up exercise could decrease the initial oxygen deficit and limit the involvement of anaerobic metabolism at the onset of exercise [2]. A warm-up that has enough intensity to elevate blood lactate concentration to approximately $2-4 \mathrm{mM} /$ lit can profoundly alter $\mathrm{VO}_{2}$ kinetics and 
has the potential to enhance exercise performance. Because the accumulation of several by-products of high-intensity exercise, including lactic acid, will increase muscle blood flow and thus make more $\mathrm{O}_{2}$ available to muscle $[7,8]$. These studies proposed that a metabolic acidosis is necessary for the $\mathrm{VO}_{2}$ response profile to be altered in the second exercise bout. But Koppo, Bouckaert [8] showed a prior sub maximal exercise similar the prior heavy exercise $\mathrm{VO}_{2}$ response was reduced during the second bout of exercise [9]. The purpose of this study was to examine the effects of prior (warm-up) exercise on pulmonary oxygen uptake at the end of sub maximal exercise in elite female futsal players.

\section{Materials and Methods}

\section{Subjects}

10 female national team Iranian futsal players volunteered and complete written informed consent to participate in this study. Their physical characteristics are presented in Table 1.

Table1: Participant's Physical characteristics, $(\mathrm{M} \pm \mathrm{SD})$.

\begin{tabular}{|c|c|}
\hline Number & $\mathbf{1 0}$ \\
\hline Age(years) & $22.5 \pm 3.2$ \\
\hline Weight $(\mathrm{kg})$ & $56.04 \pm 6.1$ \\
\hline Height $(\mathrm{cm})$ & $163 \pm 3.6$ \\
\hline BMI $\left(\mathrm{kg} / \mathrm{m}^{2}\right)$ & $21.07 \pm 2.2$ \\
\hline VO2 max $\left(\mathrm{ml}^{2} \mathrm{~kg}^{-1} \cdot \mathrm{min}^{-1}\right)$ & $46.05 \pm 4.6$ \\
\hline Fat percentage $(\%)$ & $23.5 \pm 3.8$ \\
\hline
\end{tabular}

\section{Experimental Design}

The subject's referred to the national Olympic academy of Iran on four days which was separated by $48 \mathrm{~h}$. Exercise testing was performed at approximately the same time of day for each subject and they inhibited of heavy exercise for at least $24 \mathrm{~h}$ prior to testing. In the first day subjects performed a graded exercise test to volitional fatigue for the determination of maximal oxygen uptake $\left(\mathrm{VO}_{2}\right.$ max $)$ and lactate threshold. The first stage time of test was $3 \mathrm{~min}$ for warm up at work rate $6 \mathrm{~km} / \mathrm{h}$ and then increased incrementally by $1 \mathrm{~km} / \mathrm{h}$ every $1 \mathrm{~min}$ until the subjects were unable to continue. In three subsequent next days's subjects performed two warm up protocols (moderate and heavy intensity) and without warm up randomly (cross design) before sub maximal exercise training ( $6 \mathrm{~min}$ at $80 \% \mathrm{VO}_{2}$ at LT). The heavy intensity warm up was running on treadmill by $6 \mathrm{~min}$ at $50 \%$ of the difference between the $\mathrm{VO}_{2}$ at $\mathrm{LT}$ and $\mathrm{VO}_{2}$ $\max \left[\mathrm{LT}+50 \%\left(\mathrm{VO}_{2} \max -\mathrm{LT}\right)\right.$. The moderate intensity warm up was running by $6 \mathrm{~min}$ at $80 \%$ the $\mathrm{VO}_{2}$ at LT [10]. The both two protocol of warm up was continued by $3 \mathrm{~min}$ running at $3 \mathrm{~km} / \mathrm{h}$ before the sub maximal exercise is performed. Pulmonary gas exchange was measured breath-by-breath throughout all tests by Gas Analyzer (k4b2, Italy).

\section{Data Collection}

In this study for determination of third time constant of $\mathrm{VO}_{2}$ kinetics (time of reach to $95 \%$ of total oxygen uptake) was used [11]. Also because the total oxygen uptake was not similar after three warm up protocols, we calculated $\mathrm{VO}_{2}$ to time of reach in third time constants ratio.

\section{Statistical Analysis}

The effect of prior exercise on the $\mathrm{VO}_{2}$ responses was compared using one-way repeated measures Analysis of Variance (ANOVA). When a significant difference was detected, this was further examined by post hoc LSD test. A P value of 0.05 was considered statistically significant. All statistical analyses were performed with using SPSS 16 soft were (Statistical Package for Social Science).

\section{Result}

The total oxygen uptake and third time constant values $\left(\mathrm{O}_{2}\right.$ uptake, time of reach to third time constant and $\left.\mathrm{VO}_{2} / \mathrm{t}\right)$ are presented in Table 2 . The result showed, total $\mathrm{VO}_{2}$ uptake were not significant difference after three conditions $(\mathrm{p}=0.055)$. Third time constants significantly reduced due to without warm-up $(\mathrm{p}<0 / 001)$. also oxygen uptake/time ratio in third time constants increased significantly after moderate and heavy warm up due to without warm-up $(\mathrm{p}<0 / 011)$ (Figure 1).

Table 2: Oxygen uptake kinetics (Mean $\pm S D$ ) in different stage of test.

\begin{tabular}{|c|c|c|c|c|c|}
\hline & & Without warm up & Moderate intensity warm up & Heavy intensity warm up & $P$ value \\
\hline \multicolumn{2}{|c|}{ Total oxygen uptake (ml) } & $1759.5 \pm 116$ & $1757.9 \pm 158$ & $1628.4 \pm 102$ & 0.055 \\
\hline \multirow{3}{*}{ Time constant 3} & $\mathrm{O}_{2}$ uptake $(\mathrm{ml})$ & $1674.5 \pm 113$ & $1670 \pm 150.3$ & $1547 \pm 97.8$ & 0.059 \\
\hline & Time to reach (second) & $227 \pm 69$ & $123.1 \pm 28.5^{*}$ & $129 \pm 18.9 *$ & 0.001 \\
\hline & $\mathrm{O}_{2}$ uptake/time of reaching & 7.37 & $13.56^{*}$ & $11.99 *$ & 0.011 \\
\hline
\end{tabular}




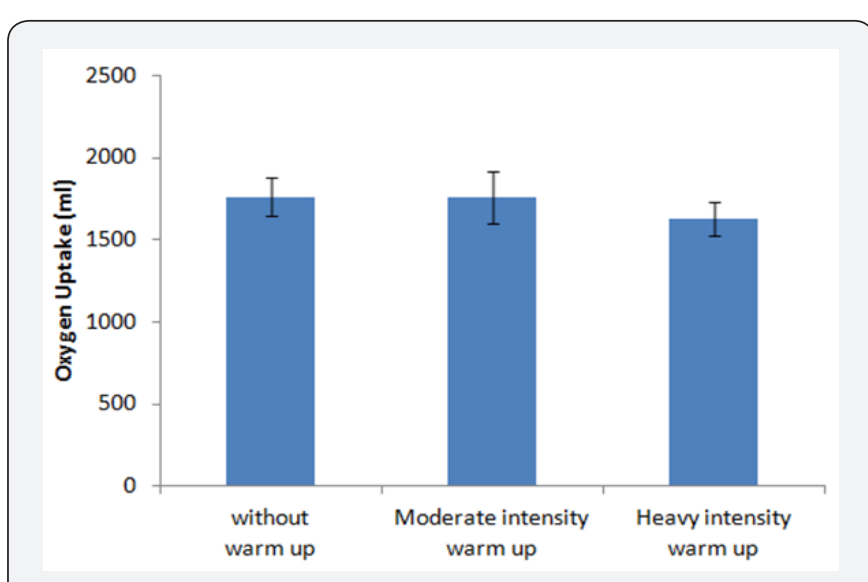

Figure 1: Total Oxygen Uptake after No Warm Up, Moderate Intensity and Heavy Intensity Warm-Up.

\section{Discussion}

The present study demonstrated that oxygen uptake in the end of sub maximal exercise after heavy intensity warm up was reduced, but was not significant difference after three conditions $(p=0.055)$. The endurance players reduced oxygen uptake in the end of exercise case improved performance. Warm-up exercise resulted in a reduced $\mathrm{O}_{2}$ deficit. A lower $\mathrm{O}_{2}$ deficit implies a smaller requirement for energy production from anaerobic sources and is consistent with the lower rate of accumulation of blood lactate measured in sub maximal exercise [1]. Regarding to results of the present study can be said to reduction in time constant significantly have reduced oxygen deficit and accumulation of metabolites and phosphorylate substrate. This expression can be supported, because total oxygen consumption was reduced at the end of exercise after heavy intensity warm up than moderate intensity warm up and without warm up. So heavy intensity warm up probably is caused reduction in oxygen consumption and improvement in movement economy in sub maximal training. Because total oxygen consumption wasn't quite the same in three warm up condition, in this study we used the oxygen consumption time constant ratio $\left(\mathrm{O}_{2}\right.$ uptake/ time of reaching), in fact these results confirmed findings what be related to time constant and also previous results that warm up can reduce time to steady state phase of $\mathrm{VO}_{2}$, and slope of diagram of $\mathrm{VO}_{2}$ was faster and in the less time more oxygen can be consumed. So $\mathrm{O}_{2}$ delivery to active muscle may be was one of the restrictions $\mathrm{VO}_{2}$ kinetics during acute training, and warm up faster of the $\mathrm{VO}_{2}$ kinetics through increased the muscle blood flow and oxygen availability [12]. Then the effects of warm up on the acceleration of $\mathrm{VO}_{2}$ kinetics can be vasodilatation; improve blood flow, right ward shift of the $\mathrm{O}_{2} \mathrm{Hb}$ dissociation curve, improved $\mathrm{O}_{2}$ off-loading from haemoglobin and improving the diffusion gradient for $\mathrm{O}_{2}$ between the capillary blood and the mitochondria of the exercising muscles [13]. Increase in oxygen availability at the beginning of exercise due to warm up cause faster stability of the intracellular and better metabolic control $[14,15]$. There is also evidence that warm-up exercise reduces the magnitude of phosphocreatine depletion during high exercise and increased mechanical efficiency of working muscle consequent to an elevated muscle temperature [12]. Also warm up reduced of accumulation lactate due to increase of oxygen available [8]. Therefore this study showed that warm up without intensity improved $\mathrm{VO}_{2}$ kinetics and oxygen uptake, and author decrease $\mathrm{O}_{2}$ deficit and improved performance.

\section{References}

1. Carter H, Jones AM, Barstow TJ, Burnley M, Williams C, et al. (2000). Effect of endurance training on oxygen uptake kinetics during treadmill running. J Appl Physiol 89(5): 1744-1752.

2. Gerbino A, Ward SA, Whipp BJ (1996) Effects of prior exercise on pulmonary gas exchange kinetics during high-intensity exercise in humans. J Appl Physiol 80(1): 99-107.

3. Whipp BJ, Ward SA, Lamarra N, Davis JA, Wasserman K (1982) Parameters of ventilatory and gas exchange dynamics during exercise. J Appl Physiol 52(6): 1506-1513.

4. McNulty CR, Robergs RA (2017) Comparisons of Vo Kinetics in Moderate-Intensity Exercise Transitions in Highly-Trained and Untrained Subjects. JEP 20(1): 249-263.

5. Rossiter HB, Ward SA, Doyle VL, Howe FA, Griffiths JR, et al. (1999) Inferences from pulmonary $\mathrm{O}_{2}$ uptake with respect to intramuscular [phosphocreatine] kinetics during moderate exercise in humans. J Physiol 518(Pt 3): 921-932.

6. Bishop D (2003) Warm up II: Performance Changes Following Active Warm up and How to Structure the Warm up. Sports Med 33(7): 483498.

7. Sousa A, Ribeiro J, Sousa M, Vilas-Boas JP, Fernandes RJ (2014) Influence of Prior Exercise on VO Kinetics Subsequent Exhaustive Rowing Performance. PLoS ONE 9(1): e84208.

8. Koppo K, Bouckaert J (2000) Inhumans the oxygen uptake slow component is reduced by prior exercise of high as well as low intensity. EUR J Appl Physiol 83(6): 559-565.

9. Bunn JA, Eschbach LC, Magal M, Wells EK (2017) The Effects of Warmup Duration on Cycling Time Trial Performance in Trained Cyclists. Central European Journal of Sport Sciences and Medicine 17(1): 5-13.

10. Brendon J Gurd, Barry W Scheuermann, Donald H Paterson, John M Kowalchuk (2004) Prior Heavy-intensity Exercise Speeds $\mathrm{VO}_{2}$ Kinetics During Moderate-intensity Exercise in Young Adults. J Appl Physiol 98(4): 1371-1378.

11. Jones AM, Poole DC (2005) Oxygen uptake kinetics in Sport, Exercise and Medicine. London and Routledge, New York, USA 4(1): 84.

12. Gurd BJ, SJ Peters, GJF Heigenhauser, LeBlanc PJ, Doherty TJ, et al. (2006) Prior heavy exercise elevates pyruvate dehydrogenase activity and speeds $\mathrm{O}_{2}$ uptake kinetics during subsequent moderate-intensity exercise in healthy young adults. J Physiol 5773(Pt 3): 985-996.

13. DeLorey DS, Kowalchuk John M, Heenan Aaron P, Dumanoir Gregory $\mathrm{R}$, Donald $\mathrm{H}$, et al. (2007) Prior exercise speeds pulmonary $\mathrm{O}_{2}$ uptake kinetics by increases in both local muscle $\mathrm{O}_{2}$ availability and $\mathrm{O}_{2}$ utilization. J Appl Physiol 103(3): 771-778.

14. Burnley Mark, Jones Andrew M, Helen Carter, Doust Jonathan H (2000) Effects of prior heavy exercise on phase II pulmonary oxygen uptake kinetics during heavy exercise. J Appl Physiol 89(4): 1387-1396.

15. Mark Burnley, Andrew M Jones (2007) Oxygen Uptake Kinetics as a Determinant of Sports Performance. European Journal of Sport Science $7(2): 63-79$. 
This work is licensed under Creative Commons Attribution 4.0 License

DOI: 10.19080/JPFMTS.2018.03.555617

\section{Your next submission with Juniper Publishers} will reach you the below assets

- Quality Editorial service

- Swift Peer Review

- Reprints availability

- E-prints Service

- Manuscript Podcast for convenient understanding

- Global attainment for your research

- Manuscript accessibility in different formats ( Pdf, E-pub, Full Text, Audio)

- Unceasing customer service

Track the below URL for one-step submission https://juniperpublishers.com/online-submission.php 